\title{
The International Association of Geodesy: from an ideal sphere to an irregular body subjected to global change
}

\author{
Hermann Drewes ${ }^{1}$ and József Ádám ${ }^{2}$ \\ ${ }^{1}$ Technische Universität München, Munich 80333, Germany \\ ${ }^{2}$ Budapest University of Technology and Economics, Budapest, P.O. Box 91, 1521, Hungary \\ Correspondence: Hermann Drewes (h.drewes@tum.de)
}

Received: 11 November 2018 - Revised: 21 December 2018 - Accepted: 4 January 2019 - Published: 16 April 2019

\begin{abstract}
The history of geodesy can be traced back to Thales of Miletus ( $\sim 600 \mathrm{BC})$, who developed the concept of geometry, i.e. the measurement of the Earth. Eratosthenes (276-195 BC) recognized the Earth as a sphere and determined its radius. In the 18th century, Isaac Newton postulated an ellipsoidal figure due to the Earth's rotation, and the French Academy of Sciences organized two expeditions to Lapland and the Viceroyalty of Peru to determine the different curvatures of the Earth at the pole and the Equator. The Prussian General Johann Jacob Baeyer (1794-1885) initiated the international arc measurement to observe the irregular figure of the Earth given by an equipotential surface of the gravity field. This led to the foundation of the International Geodetic Association, which was transferred in 1919 to the Section of Geodesy of the International Union of Geodesy and Geophysics. This paper presents the activities from 1919 to 2019, characterized by a continuous broadening from geometric to gravimetric observations, from exclusive solid Earth parameters to atmospheric and hydrospheric effects, and from static to dynamic models. At present, we identify geodesy as the discipline of quantifying global change by geodetic measurements.
\end{abstract}

\section{Introduction: historical background}

Geodesy, the discipline of measuring and representing the Earth's surface, is one of the oldest sciences (e.g. Torge and Müller, 2012). Thales of Miletus ( 624-546 BC) developed the concepts of geometry, i.e. the measurement of the Earth, which he regarded as a disk floating on the oceans, and Pythagoras of Samos $(\sim 580-500 \mathrm{BC})$ considered the Earth an ideal sphere levitating in space. Aristotle (384-322 BC) defined geodesy as the practical application of geometry, and Eratosthenes of Cyrene (276-195 BC) was the first to estimate the radius of a spherical Earth by astronomic and geodetic observations (Fig. 1).

Claudius Ptolemy $(\sim 100-160$ AD) realized a geocentric world system by a catalogue of about 6300 locations with geographic coordinates (Kleineberg et al., 2011) and depicted them on maps. This system was valid until the end of the Middle Ages, when Nicolaus Copernicus (1473-1543) proposed the heliocentric system with a spherical Earth in an elliptical orbit around the Sun. Isaac Newton (1643-1727) raised the discussion on the figure of the Earth again by his physical model of an ellipsoid as the equilibrium figure of a rotating Earth, i.e. a flattening of the Earth at its rotation poles. Measurements of the differing curvatures of the meridian at the North Pole (Lapland, 1736-1737) and the Equator (Viceroyalty of Peru, 1735-1744) performed by the French Academy of Sciences (Fig. 2, left) confirmed this model.

In the following decades there was considerable activity observing the curvature of meridians (i.e. the deflection of the vertical $\varepsilon$, Fig. 2, right) in many geographic locations. Astronomic observations at the end points ( $\mathrm{a}$ and $\mathrm{b}$ or $\mathrm{c}$ and $\mathrm{d}$, respectively) of the meridian arc provide the natural latitude difference $\Delta \Phi$; geodetic triangulation yields the latitude difference $\Delta \varphi$ on the ellipsoid. The difference $\varepsilon=\Delta \Phi-\Delta \varphi$ is the so-called deflection of the vertical, which shows significant differences in varying regions. Carl Friedrich Gauss (1777-1855) concluded that this is due to the geographically varying gravity of the Earth, and that the true figure of the Earth is given by the ocean under calm conditions (without tides, currents etc.). Gauss' student Johann Benedict Listing 


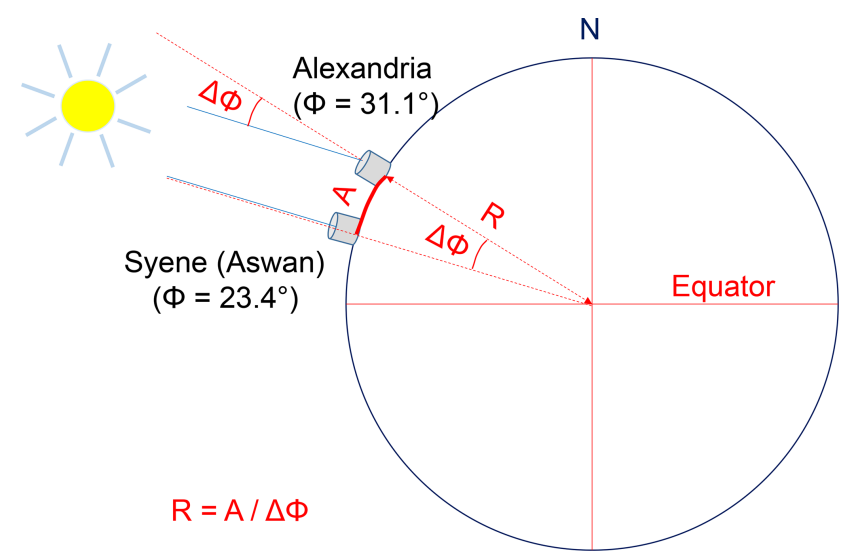

Figure 1. Eratosthenes' method of determining the radius of a spherical Earth. At the summer solstices the Sun is mirrored in a water supply well in Syene (today's Aswan High Dam), but in Alexandria, located on the same meridian, the Sun is casting a shadow with a length corresponding to an angle of $\Delta \Phi=7.7^{\circ}$, i.e. the latitude difference between both locations. Measuring the distance from Alexandria to Syene (arc A) yields the Earth's radius $R=A / \Delta \Phi$.

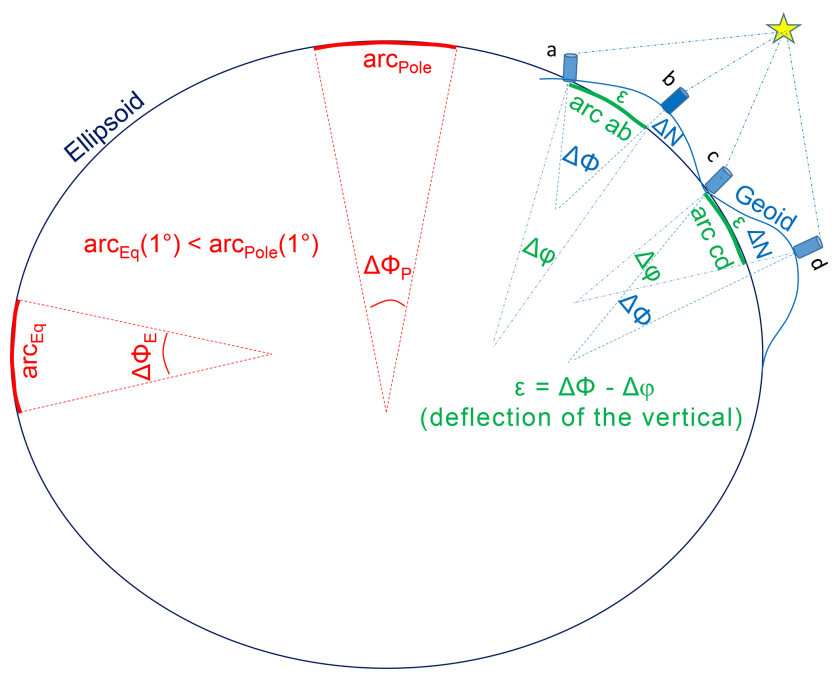

Figure 2. Determination of the flattening of the ellipsoid (left) and the varying curvature of the meridian (right) from astronomic $(\Delta \Phi)$ and geodetic (ellipsoidal $\Delta \varphi$ ) meridian arc measurements showing different deflections of the vertical $\varepsilon$ and geoid heights $N$.

(1808-1882) called the corresponding surface the "geoid". Geoid height differences $(\Delta N)$ result from multiplying the deflection of the vertical by the arc length. The determination of the geoid became a fundamental challenge of geodesy, as it is till the present, because all concepts related to water surfaces (oceans, lakes, rivers, and channels, down to waterlevel bubbles for levelling the geodetic instruments) and the physical heights orient themselves to the geoid.

Johann Jacob Baeyer (1794-1885) wrote a memorandum "On the size and figure of the Earth" (Baeyer, 1861) as motivation for a project for the "Central European arc measure- ment". By the end of 1862, 15 states had signed an intergovernmental agreement and an association was formally established at the General Conference in Berlin 1864. IUGG's International Association of Geodesy (IAG) considers these years to be its origin (Helmert, 1913; Tardi, 1963; Torge, 2016). The association was extended to all of Europe in 1867 and to the worldwide "Internationale Erdmessung" (International Geodetic Association) in 1886. The intergovernmental convention was renewed every 10 years; however, at the end of 1916 it expired because of World War I.

\section{Transition to the IUGG Section of Geodesy}

In 1917, the President of the International Geodetic Association, Léon Bassot, and the Director of the Central Bureau, Friedrich Robert Helmert, passed away. The Vice-President, Oskar Backlund, had died in 1916. Two persons guaranteed the continuation of the geodetic activities by proposing the "International Geodetic Association of Neutral Nations": Raoul Gautier (Switzerland, 1854-1931) as the new President and Hendricus Gerardus van de Sande Bakhuyzen (the Netherlands, 1839-1923) as the Secretary since 1900. Six states (Denmark, the Netherlands, Norway, Spain, Sweden, and Switzerland) and the Central Bureau in Potsdam, Germany, continued the administration, measurements, and data analyses, in particular those of the International Latitude Service, from 1917 to 1921, despite the war (Krüger, 1922; Levallois, 1980; Torge, 2005).

In January 1918, the French geodesist Charles Lallemand (1857-1938) sent a draft convention for a new international geodetic association to the delegates of the former association. He denounced the self-styled Association of Neutral Nations and the continued activity of the Central Bureau in Germany, and pushed for the exclusion of the former German and Austro-Hungarian empires (Levallois, 1980). Raoul Gautier objected judiciously, correcting some exaggerations, but the draft formed finally the basis of discussion at the conferences in London and Paris in 1918 that led to the foundation of the International Union of Geodesy and Geophysics (IUGG) with the Section of Geodesy in Brussels 1919. This Union included only allied and neutral nations of World War I (Angus-Leppan, 1984).

The IUGG constituent assembly in Brussels 1919 appointed Charles Lallemand President of the new Union, and William Bowie (1872-1940), the USA representative to the International Geodetic Association, President of the Section of Geodesy. The French Geodesist Georges Perrier (18731946), experienced in international cooperation in African, American, and European (Balkan) countries (Perrier, 1923), and very active in the preparation of the assembly (Boucher and Willis, 2016), was appointed the Section's Secretary General. These appointments were temporary, to be confirmed at the first General Assembly. 
The IUGG Section of Geodesy held its constituent assembly during the first IUGG General Assembly from 4 to 9 May 1922 in Rome. Fifty-nine delegates represented 23 countries (Europe 15, Africa 1, Asia 1, Australia 1, North America 3, and South America 2). There were seven halfday sessions dealing with (I) administrative and organizational topics, (II) national reports, (III) scientific issues, and (IV) international operations.

Administrational and organizational themes defined the basics of the Section. These were the following.

1. The statutes and organization of the Section, which were entrusted to a commission.

2. The Vice-President of the Section with the election of Raoul Gautier, former President of the previous International Geodetic Association of Neutral Nations.

3. Financial issues, where the Secretary General George Perrier explained the financing via the IUGG membership fees of the countries, as it continues until the present.

4. Publications, with the decision to create a geodetic bulletin (Bulletin Géodésique) for periodic publications, including the proceedings (Comptes Rendus) of the general assemblies. This serial exists to today, renamed the Journal of Geodesy.

5. The maintenance of international services, such as the International Latitude Service, which was established in 1899 by the International Geodetic Association.

6. Proposed activities of the Section were identified:

- observations and theories on the deflections of the vertical,

- gravity intensity (on land and sea),

- isostasy,

- Earth tides,

- shape of the geoid, and

- stability of the Earth in time.

National reports to the General Assembly were published in another series, the Travaux de la Section de Géodésie. The first issue started with a report on the activities of the International Geodetic Association from 1912 to 1922 (van de Sande Bakhuyzen, 1923), followed by the reports of the participating countries. This publication series continues until the present, changed from national reports to the reports of the IAG components.

Scientific issues focussed on international rules and definitions for

- fixing the density and precision of triangulation points, baselines, astronomic coordinates, etc.;
- minimum details to be included in publications of different works;

- choice of an international reference ellipsoid;

- choice of a unique map projection system;

- lines to follow or regions to explore for the geoid and gravity anomalies' determination; and

- a bibliography of geodesy.

International operations dealt in general with the connection of triangulation networks in different countries to be organized by the Section, e.g. in Belgium and France, Sardinia and Liguria, Cairo and Europe. This was in principle a continuation of the work initiated by the Central European Arc Measurement in 1862, and continued until 1921.

\section{IUGG Section of Geodesy between the World Wars (1922-1939)}

The structure of the Section of Geodesy for the first period 1922-1924 was based upon 10 rapporteurs for the essential geodetic problems at that time: triangulation and bases, precise levelling, geodetic astronomy, deflections of the vertical, gravity intensity, isostasy, latitude variation, projections, Earth tides, and stability of the Earth in time. Two commissions were established to study (1) the general requirements of geodetic research and (2) the publication of primary values of the trigonometric lines, which were originally given in different units, in the decimal system. Two permanent commissions on latitudes and longitudes were set up in cooperation with the new International Astronomical Union (IAU), the International Latitude Service (ILS) of the International Geodetic Association (since 1899), and the Bureau International de l'Heure (BIH) established in 1912 (Guinot, 2000).

At the General Assembly in Madrid 1924, the Section's Statutes were adopted defining the decision-making, administrative, and scientific structure. These were

- the Bureau, composed of the elected President, VicePresident, and Secretary General,

- the Secretariat, responsible for correspondents, budget, publications, archives, etc.,

- the Executive Committee, composed of the Bureau and four elected members,

- the Permanent Commission, composed of one delegate of each member country,

- the General Assembly, composed of all the delegates of the member countries, and

- the Scientific Commissions performing the Section's geodetic activities. 
One of the most important decisions for science and practice was the adoption of the Hayford spheroid as the International Reference Ellipsoid 1924. Important innovations were the gravity meters on land (spring gravimeters) and at sea (Vening-Meinesz pendulum). Eighteen commissions were set up in 1924 and continued until 1933, and with small modifications until 1946. Table 1 lists those commissions. There were also two joint commissions together with the Section of Physical Oceanography on variations of the mean sea level, and the Sections of Seismology and Volcanology on studies of the Earth's crust.

Besides the modifications in the Commission's structure, there was a change in the officers of the Section in 1933. William Bowie was elected IUGG President and Raoul Gautier had passed away in 1931. The Section elected Felix A. Vening-Meinesz as the new President and Walter D. Lambert as Vice-President. George Perrier continued as the Secretary General. The Washington 1939 General Assembly started 3 days after the beginning of World War II. The programme was substantially changed and reduced, and the scheduled elections were suspended. The organizational status remained thus until 1946. The officers are listed at https://iag.dgfi.tum.de/en/ iag-history-photos-of-the-presidents-and-secretaries/ (last access: 15 February 2019).

\section{The re-establishment of the International Association of Geodesy after World War II}

Immediately after the end of World War II, in December 1945, the IUGG Executive Committee met in Oxford to discuss the continuation of the Union and convened an extraordinary General Assembly in Cambridge, in July 1946. The IUGG Section of Geodesy had been renamed the "International Association of Geodesy (IAG)", and its Permanent Commission met in August 1946. The Secretary General George Perrier had died in February 1946, and Pierre Tardi was elected as his successor. The principal decision of the meeting was to establish a general scientific structure composed of five Sections. The General Assembly in Oslo 1948 ratified these Sections, which remained until 1963:

- Section I: Triangulations;

- Section II: Precise Levelling;

- Section III: Geodetic Astronomy;

- Section IV: Gravimetry;

- Section V: Geoid.

Section I dealt with the activities started in the early years of international cooperation in geodesy and carried out by the IUGG Section of Geodesy since 1922, i.e. the connection of national networks. A first important project after World War II was the Réseau Européen de Triangulation
(RETrig). The US Army Map Service (AMS) ordered in 1947 the creation of a unified net in Europe and realized it initially by the European Datum 1950 (ED50). The IAG was reluctant to work on a military project; however, a resolution at the General Assembly in Brussels 1951 advocated a scientific continuation. A challenge was the use of the upcoming electronic and electro-optic distance measurements superseding the triangulation baselines and leading to trilateration. Another major topic was the reduction of the observations to the ellipsoid, i.e. the requirement for orthometric heights and geoid models. The availability of the first electronic calculators encouraged the development of novel adjustment procedures.

The focus of precise levelling was the analysis of systematic errors, in particular caused by the atmospheric refraction, and referring the surface measurements to the geoid through a gravity reduction process. These topics were of special importance for the connection of national levelling networks. European countries decided in 1955 to establish a unified European levelling network (Réseau Européen Unifié de Nivellement, REUN) and to use geopotential numbers instead of orthometric or dynamic heights. The first connections of neighbouring national networks showed significant discrepancies, which led to the detection of different mean sea levels at the reference tide gauges. A preliminary list of such offsets was presented at the General Assembly in Toronto 1957.

The geodetic astronomy discussion concentrated on different instruments and methods of latitude, longitude, and azimuth determination. The major error source arising from time transfer could be improved by using oscillography; i.e. the time signal was recorded in order to trace irregularities. Results of measurements with a new instrument, the zenith camera, showed promising results for simultaneous determination of latitude and longitude. Section III planned with the ILS a special activity for observing polar motion in the framework of the International Geophysical Year 1957/58, in cooperation with other astronomical, geophysical, and meteorological unions and associations. At the General Assembly in Helsinki 1960 there was for the first time a discussion on using artificial satellites instead of celestial bodies.

Gravimetry had referred since 1909 to the Potsdam absolute pendulum measurements (Potsdam Gravity System). Connecting observations at Washington and LondonTeddington with the Potsdam Observatory had already shown in the 1930s significant discrepancies. Free-fall measurements in Paris-Sèvres, Leningrad, and Ottawa from 1952 to 1958 confirmed these deviations. Many countries installed calibration lines for adjusting their gravimeters. In order to cover the entire Earth's surface, gravity measurements at sea and in the air were advanced. The Bureau Gravimetrique International (BGI) has collected these data since 1951.

Classical geoid determination is restricted to regional computations using the astro-geodetic techniques combining deflections of the vertical derived from astronomical obser- 
Table 1. Commissions active in the period from 1924 to 1939.

\begin{tabular}{|c|c|}
\hline Commission name & Comments \\
\hline \multicolumn{2}{|l|}{ Finances } \\
\hline Original values of trigonometric lines in decimal system & 1933 renamed Bibliography \\
\hline The Invar & 1933 renamed Triangulation \\
\hline Intensity of gravity & 1933 split into land and sea \\
\hline \multicolumn{2}{|l|}{ Latitudes } \\
\hline \multicolumn{2}{|l|}{ Longitudes } \\
\hline \multicolumn{2}{|l|}{ Projections } \\
\hline \multicolumn{2}{|l|}{ Tides of the Earth crust } \\
\hline Problems also of interest for Seismology and Volcanology & 1927 discontinued \\
\hline International regulation of geodetic works & 1933 discontinued \\
\hline Examine the establishment of topographic and oceanic maps & 1933 discontinued \\
\hline \multicolumn{2}{|l|}{ Junction of Belgian and French triangulations } \\
\hline Junction of French and Italian triangulations & 1933 discontinued \\
\hline Junction of triangulations of Sardinia, Liguria and Corsica & 1933 discontinued \\
\hline \multicolumn{2}{|l|}{ Junction of Spanish and French triangulations to Morocco } \\
\hline \multicolumn{2}{|l|}{ Junction of the Meridian arc of Capetown via Cairo to Europe } \\
\hline \multicolumn{2}{|l|}{ The Meridian arc from the arctic ocean to the Mediterranean } \\
\hline \multicolumn{2}{|l|}{ The Meridian arc traversing Siam and neighbouring countries } \\
\hline Precise levelling & established 1930 \\
\hline Time & established 1933 \\
\hline Arc of a mean parallel & established 1933 \\
\hline Study of a joint adjustment of the European network & established 1933 \\
\hline Notations & established 1936 \\
\hline Geoid & established 1936 \\
\hline
\end{tabular}

vations with triangulation results (see Fig. 2). Discussions on this method continued in Section V until more and more gravity observations became available. Heiskanen published in 1957 a global geoid using all available gravity data in a grid of 6679 geographic $1^{\circ} \times 1^{\circ}$ blocks (Fig. 3). Discussions focussed on the applied methods, e.g. Stokes' integral, spherical harmonics, and least squares collocation.

\section{The inception of the space age in geodesy (1963-1983)}

The General Assembly in Berkeley 1963 adopted a fundamental change in the IAG structure due to the launch of artificial satellites for geodetic applications. In particular, the NASA balloon satellites provided epoch-making results, as they enabled for the first time direct intercontinental observations for point positioning with a considerable impact on the classical methods of triangulation and geodetic astronomy. With more and more precise geodetic observations, changes in the geometry of the Earth's surface could be measured, at first in the vertical direction. Consequently, the structure of the IAG Sections required change from the Triangulations Section to the more general Geodetic Positioning Section, adding artificial satellites to Section III, augmenting the Levelling Section with the topic of Crustal Motion, and broadening the Geoid Section to Physical Geodesy. The new structure comprised
- Section I: Geodetic Positioning;

- Section II: Levelling and Crustal Motion;

- Section III: Geodetic Astronomy and Artificial Satellites;

- Section IV: Gravimetry; and

- Section V: Physical Geodesy.

Geodetic Positioning continued with the adjustment of continental triangulation networks, now more concentrating on electronic distance measurements via trilateration. The error analyses and methods of adjustment were major research topics. Observations of artificial satellites were limited in the decade of the 1960s to those based on geometric methods, for example, satellite triangulation based on photographs of the 30 to $40 \mathrm{~m}$ diameter balloon satellites ECHO I (launched 1960), ECHO II (1964), and PAGEOS (1966) against the background of stars. Continental- and global-scale networks were observed.

As repeated levellings demonstrated significant height changes, countries started re-measuring their national levelling networks and interpreting the variations with respect to vertical motions of the Earth's crust. The Commission on Recent Crustal Movements (CRCM), established in 1960, collected these data and published maps of observed height changes. 


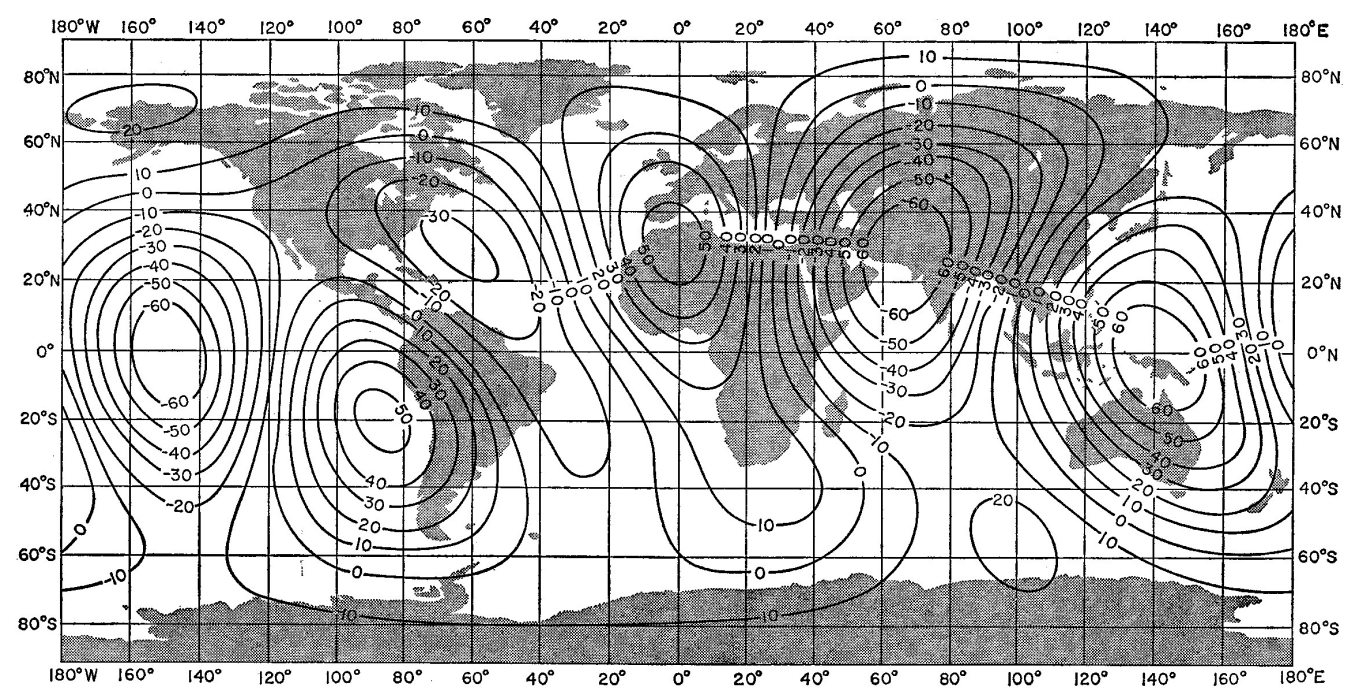

Figure 3. The Columbus geoid (Heiskanen, 1957).

Astronomical activities continued with latitude and longitude observations in cooperation with the ILS, which changed its name to the International Polar Motion Service (IPMS) in 1962. During the 1960s the most significant result in the use of artificial satellites was global satellite triangulation. International partners established cameras around the globe and placed the photographic plates at the disposal of various analysis centres. The result was a global network of 45 station positions with accuracies from \pm 2 to $8 \mathrm{~m}$ (Fig. 4).

The main activity in gravimetry in the 1960s was the observation of the global gravity network with absolute (pendulum) and relative (spring gravimeter) measurements. Many calibration lines served for standardizing the gravimeter scales. The International Gravity Standardization Net 1971 (IGSN 71) was the result of a common adjustment of observations over 17 years.

The Physical Geodesy Section dealt with theoretical and numerical studies on the geometry and gravity field of the Earth. A primary result was the Geodetic Reference System 1967 (GRS 67) defining the fundamental conventional parameters of the Earth: the semi-major axis $a$, the dynamical form factor $J_{2}$, the geocentric gravitational constant GM, and the angular velocity of the Earth's rotation $\omega$.

At the General Assembly in Moscow 1971, there was another change in the structure of sections, giving more emphasis to and broadening of space techniques and its applications:

- Section I: Control Surveys;

- Section II: Space Techniques;

- Section III: Gravimetry;

- Section IV: Theory and Evaluation;

- Section V: Physical Interpretation.
Levelling was subsumed into the Control Surveys Section, and the principal fields of study persisted in adjustments of triangulation/trilateration and levelling networks, with a focus on the specific challenges of atmospheric refraction and least squares adjustment.

Space techniques concentrated on the satellite Doppler and laser technologies, and laser ranging to the moon was commenced. There were Doppler observation campaigns in all the continents during the 1970s, yielding a precision at the decimetre level, i.e. 1 order of magnitude better than optical satellite triangulation. At the start of the 1980s, the global laser ranging network provided station coordinates at the centimetre level (Fig. 5, Christodoulidis et al., 1984).

Gravimetry concentrated on absolute gravity meters, in particular the transportable free-fall and symmetric rise-andfall instruments. The precision increased significantly during the 1970s. Precise repeated relative measurements showed significant gravity variations in tectonically active regions (such as Iceland and the South American Andes). Marine gravimetry was improved and extended over all the oceans.

The newly established Section on Theory and Evaluation studied mathematical methods in geometric and gravimetric (particularly in electronic) data processing. The necessity for a reliable Geodetic Reference System led to the revision of the GRS 1967 and the release of the updated GRS 80, which is still valid.

The Physical Interpretation Section aimed to model geophysical parameters from geodetic observations with special interest in solid Earth tides, geoid and gravity anomalies, recent crustal movements, and mean sea level (jointly with the International Association for the Physical Sciences of the Oceans, IAPSO). 


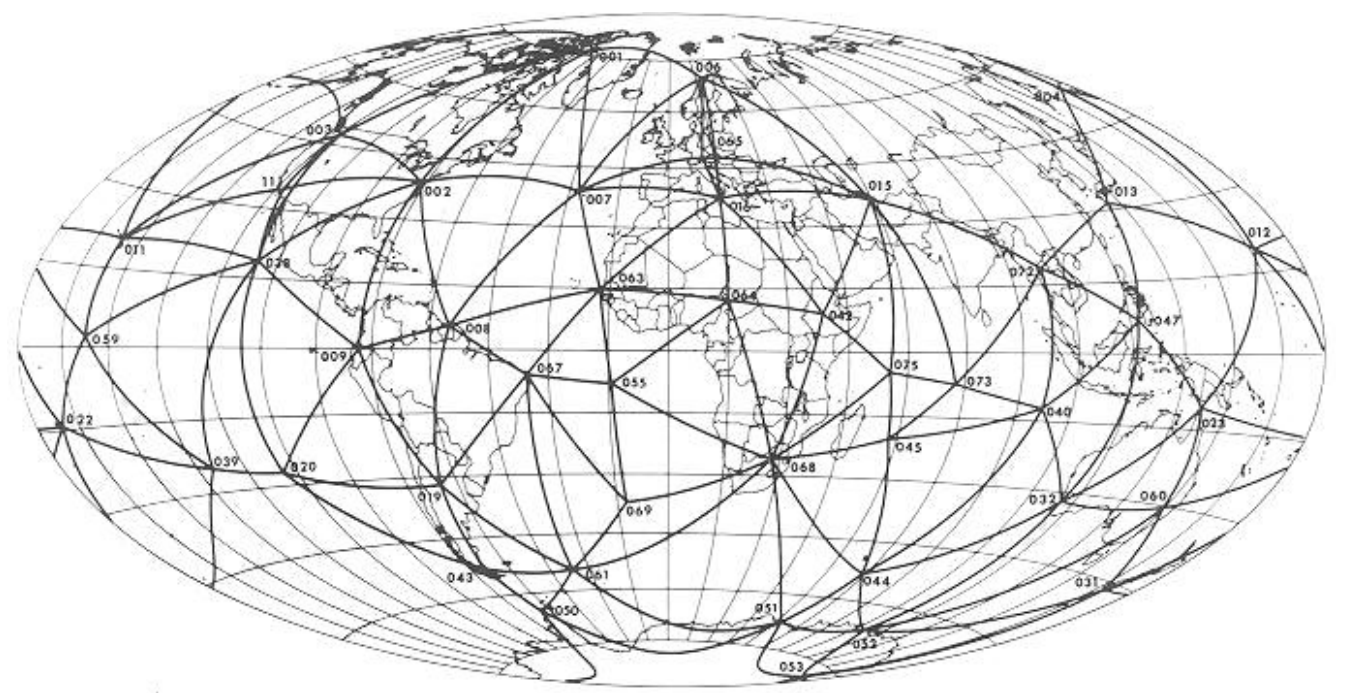

Figure 4. Global network based on satellite triangulation with an accuracy of $\pm 2-8 \mathrm{~m}$ (Schmid, 1974).

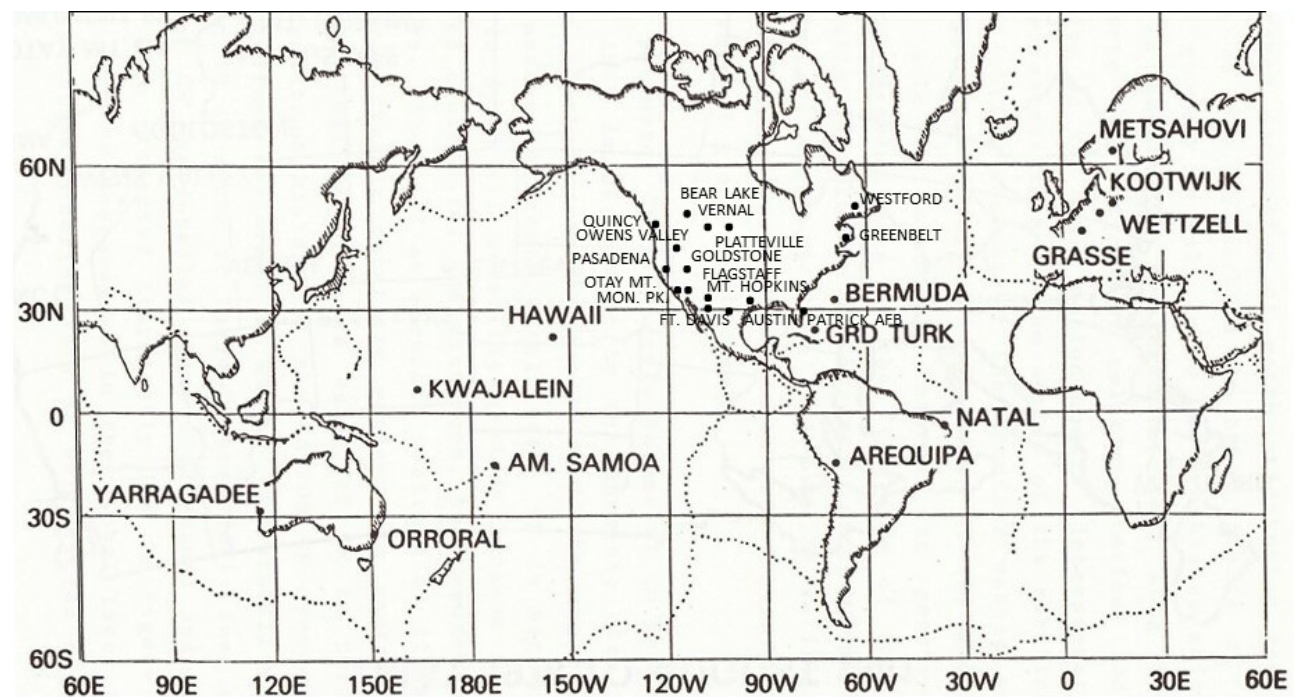

Figure 5. Satellite laser ranging network in the early 1980s (Christodoulidis et al., 1984).

\section{Geodynamic research with geodetic techniques and IAG Services (1983-2003)}

The IAG structure adopted at the General Assembly in Hamburg 1983 was substantially a specification of the sections' names, with the research fields remaining in essence as before:

- Section I: Positioning;

- Section II: Advanced Space Technology;

- Section III: Determination of the Gravity Field;

- Section IV: General Theory and Methodology;

- Section V: Geodynamics.
Section I continued studies on triangulation and levelling, and their applications in its Commission X, "Continental Networks", with sub-commissions established for all continents. Study Groups investigated network design, inertial techniques, and atmospheric effects. Satellite positioning was initially integrated into Section II. GPS theoretical studies started in Section I in 1983, its application for continental GPS networks in 1987 in its Commission X.

The geodetic space techniques and its applications were treated in Section II, in particular in its Commission VIII, "Coordination of Space Techniques for Geodesy and Geodynamics" (CSTG). It started with Doppler campaigns, followed by satellite laser ranging (SLR), very long baseline interferometry (VLBI), and the Global Positioning System 


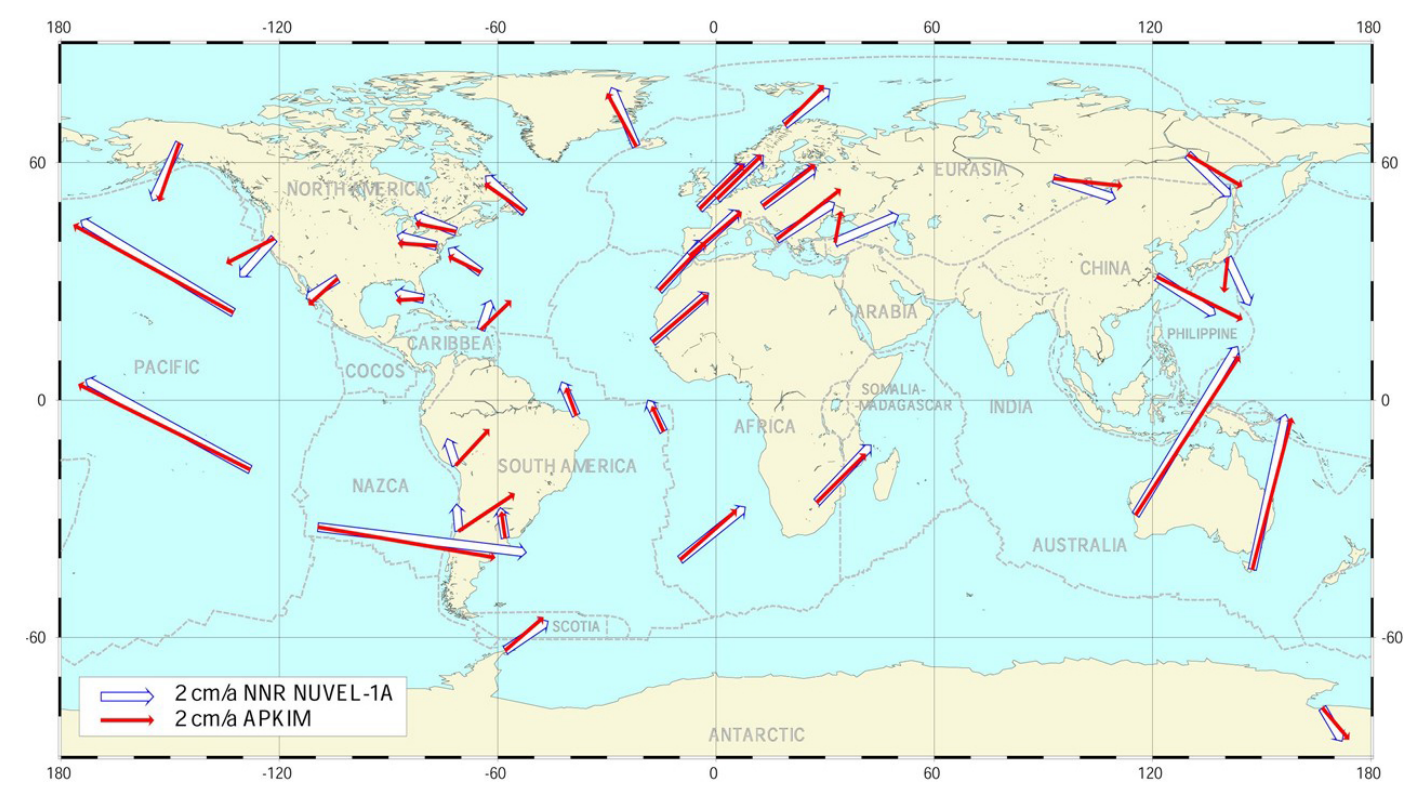

Figure 6. Comparison of actual plate kinematic models (APKIMs) from geodetic observations with a geophysical plate motion model (NNR-NUVEL-1A) derived from observations over millions of years (Drewes, 1998).

(GPS). IAG International Services for these techniques (Table 2) were initiated by the CSTG (Beutler, 2000).

Section III expanded from terrestrial gravimetry, now concentrating on absolute gravimeters, to global gravity field determination including airborne and space measurements. The International Geoid Service (IGeS) was established in 1991 to collect and analyse regional geoid computations. Many study groups investigated specific modelling problems.

Studies of the general theory and methodology of geodetic techniques and parameter estimation focussed on space techniques with respect to the boundary value problem, gravity field modelling, differential geometry, relativity, wave propagation, and transformations.

The geodynamic phenomena were traditionally Earth rotation and tides. The International Centre for Earth Tides (ICET), International Polar Motion Service (IPMS), and Bureau International de l'Heure (BIH) were consequently affiliated with Section V. Other services were the Permanent Service for Mean Sea Level (PSMSL), the International Centre on Recent Crustal Movements (ICRCM), and the Global Geodynamics Project (GGP).

The IAG Services collected and analysed a range of measurement types, and estimated corresponding parameters. An example of recent crustal movements is the comparison of geophysical and geodetic models of tectonic plate motions (Fig. 6). The IPMS and BIH merged in 1987 to become the International Earth Rotation and Reference Systems Service (IERS), which took over the task of combining results of the geometric space techniques (SLR, VLBI, GPS, DORIS) previously done by the BIH. The first International Terrestrial
Reference Frame (ITRF), computed from these data, was released in 1988.

\section{The Global Geodetic Observing System (2003-2019)}

A new IAG structure was adopted at the General Assembly in Sapporo 2003 (Beutler et al., 2004). The Sections, which included Commissions, Special Commissions, Special Study Groups, Working Groups, and Services, were restructured into Commissions and Services, and theory was concentrated in an Inter-Commission Committee. The Global Geodetic Observing System (GGOS) is coordinating products of the above-mentioned components:

- Commission 1: Reference Frames;

- Commission 2: Gravity Field;

- Commission 3: Earth Rotation and Geodynamics;

- Commission 4: Positioning and Applications;

- Inter-Commission Committee on Theory (ICCT);

- Global Geodetic Observing System (GGOS).

Reference frames form the basis for all geodetic parameters. Station coordinates and their changes in time (i.e. their velocities) are computed as multi-year solutions incorporating technique-specific solutions from the IAG Services in close cooperation with the IERS. The latest result is shown in Fig. 7. 
Table 2. IAG Scientific Services (Status 2018).

\begin{tabular}{lcl}
\hline Name & Year & Principal geodetic products \\
\hline Bureau International des Poids et Mesures (BIPM) & 1875 & Metre convention, time parameters \\
Permanent Service of Mean Sea Level (PSMSL) & 1933 & Sea level heights at tide gauges \\
Bureau Gravimétrique International (BGI) & 1951 & Gravity values from terrestrial data \\
Int. Earth Rotation \& Reference Systems Service (IERS) & 1987 & ILS/IPMS (1899/1962), BIH (1912) \\
International Service for the Geoid (ISG) & 1991 & Regional geoid models \\
International GNSS Service (IGS) & 1994 & Satellite orbits, clocks, coordinates \\
International Laser Ranging Service (ILRS) & 1998 & Geocentric station coordinates \\
International Digital Elevation Model Service (IDEMS) & 1999 & Digital terrestrial elevation models \\
Intern. VLBI Service for Geodesy \& Astrometry (IVS) & 1999 & Earth orientation, rotation, coordinates \\
International DORIS Service (IDS) & 2003 & Doppler satellite orbits, coordinates \\
International Centre for Global Earth Models (ICGEM) & 2003 & Compare global gravity models \\
International Gravity Field Service (IGFS) & 2004 & Coordinate gravity field products \\
Intern. Geodynamics and Earth Tide Service (IGETS) & 2016 & ICET (1956), GGP (1997) \\
\hline
\end{tabular}

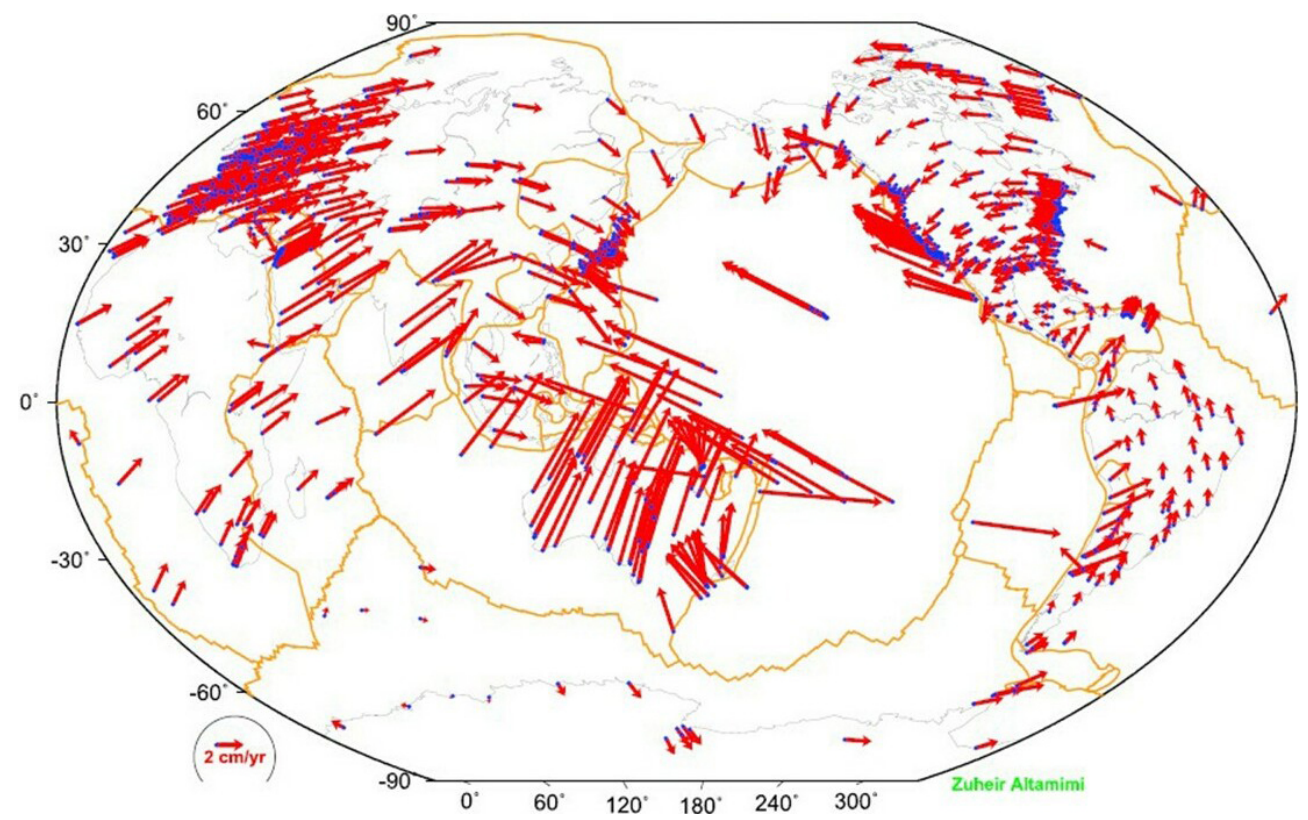

Figure 7. Station velocities of ITRF2014 (Altamimi et al., 2016).

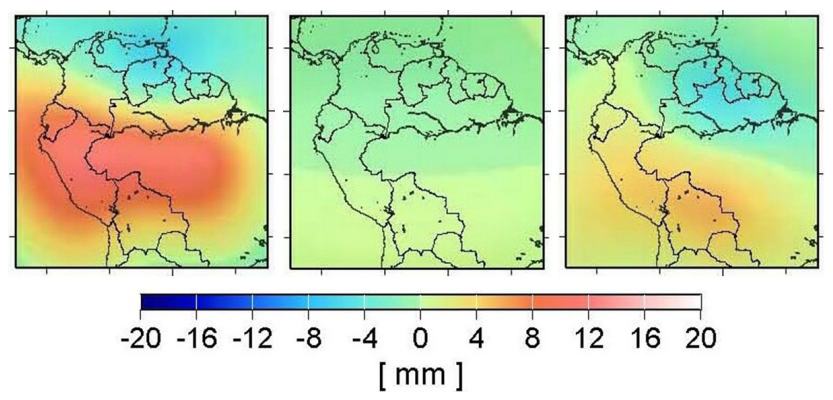

Figure 8. Geoid heights from 10-day solutions of GRACE observations in May (wet season, left), September (dry season, middle), and December (right) 2003 (Schmidt et al., 2006).
The Gravity Field Commission studies terrestrial, marine, airborne, and space observations and computes static and time-dependent global and regional gravity field models in close cooperation with the Global Gravity Field Service (IGFS). Figure 8 shows an example of temporal regional geoid variations due to hydrologic effects in the Amazon region.

Earth rotation includes the time-dependent Earth orientation in space (precession/nutation, Universal Time) and relative to the Earth's body (polar motion). Deformations include plate tectonic motions (cf. Fig. 6), crustal deformations, and sea surface variations. The studies are carried out in cooperation with the IAG Services and the International Astronomical Union (IAU). 


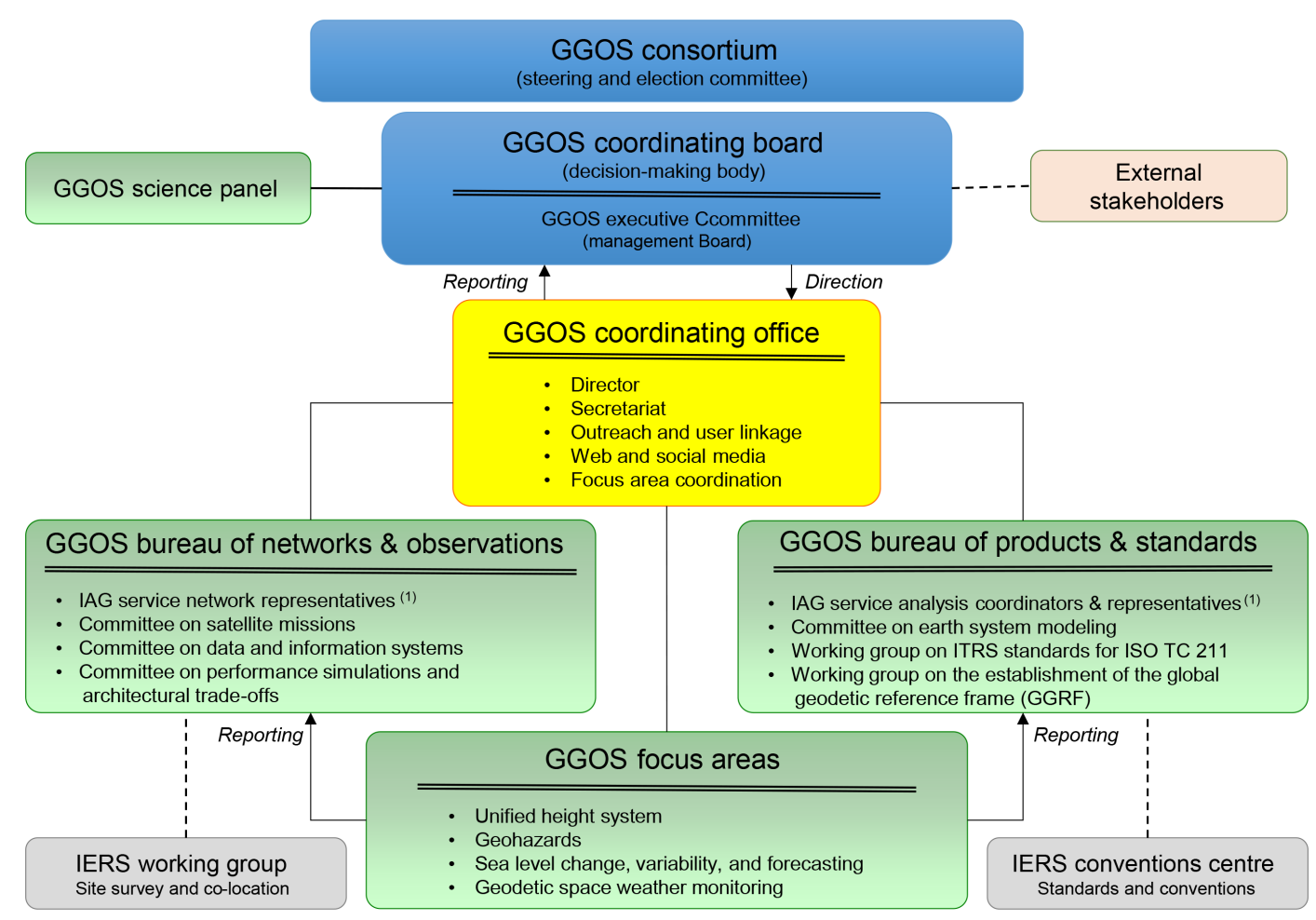

Figure 9. Structure of IAG's Global Geodetic Observing System (GGOS).

Geodetic positioning is applied in many disciplines, e.g. navigation, engineering, topography, and atmosphere remote sensing. Commission 4 studies the techniques (such as GNSS, remote sensing, or unmanned aerial vehicles - UAV) and the modelling in close cooperation with the corresponding IUGG Associations and external societies (in particular the International Federation of Surveyors, FIG).

ICCT acts as the international focus for theoretical geodesy, monitoring developments in geodetic methodology and encouraging the study of mathematical and physical problems in all fields of geodesy by means of Joint Study Groups with the Commissions and Services.

GGOS is the flagship of IAG, established to monitor the geodetic and geodynamic properties of the Earth as a system in cooperation with the Commissions and Services (Beutler et al., 2005). Its mission is

- to provide the observations needed to monitor, map, and understand changes in the Earth's shape, rotation, and mass distribution;

- to provide the global geodetic frame of reference that is the fundamental backbone for measuring and consistently interpreting key global change processes and for many other scientific and societal applications; and

- to benefit science and society by providing the foundation upon which advances in Earth and planetary system science and applications are built.
An overview of the GGOS structure is presented in Fig. 9.

\section{Conclusion and outlook}

Geodesy has changed dramatically during the latest century, which is mainly due to three extraordinary developments:

1. the advent of artificial satellites and its geodetic applications;

2. the very precise measurement of time (all modern geometric and gravimetric measurements are based on travel time measurements); and

3. the evolving information technology to process the large amount of data generated by geodetic techniques. Here, modern AI technologies offer interesting perspectives to handle the rapidly growing number of monitoring data.

The challenge to the IAG is using these achievements for the reliable measurement and representation of global change parameters. Future work shall concentrate on new satellite technologies and concepts (mini and micro satellites), quantum technology, new sensors, and micro-electro-mechanical systems (MEMS). The first steps in this direction are written in a strategy discussion of the IAG Executive Committee, which will be presented at the General Assembly in Montreal, July 2019. 
Detailed descriptions of IAG activities are published in the quadrennial Geodesist's Handbook and the biannual IAG Reports (Travaux de l'AIG), both available at https://iag.dgfi. tum.de (last access: 15 February 2019). A summary of the IAG administrative history is given in Drewes and Adam (2016).

Data availability. There are original data used in this paper. It is a historical report. If results are cited, they are based on data of the cited literature.

Competing interests. The authors declare that they have no conflict of interest.

Special issue statement. This article is part of the special issue "The International Union of Geodesy and Geophysics: from different spheres to a common globe" (https://www.hist-geo-space-sci.net/special_issue996.html). It is not associated with a conference.

Edited by: Jo Ann Joselyn

Reviewed by: Chris Rizos and one anonymous referee

\section{References}

Altamimi, Z., Rebischung, P., Metivier, L., and Collilieux, X.: ITRF2014: A new release of the International Terrestrial Reference Frame modeling nonlinear station motions, J. Geophys. Res., 121, 6109-6131, https://doi.org/10.1002/2016JB013098, 2016.

Angus-Leppan, P.-V.: A note on the history of the International Association of Geodesy, Bull. Geod., 58, 224-229, 1984.

Baeyer, J. J.: Ueber die Grösse und Figur der Erde, eine Denkschrift zur Begründung einer mitteleuropäischen Gradmessung, Verlag Georg Reimer, Berlin, 1861.

Beutler, G.: IAG services in the current framework of the International Association of Geodesy (IAG), IAG Symp., 121, 419-423, 2000.

Beutler, G., Drewes, H., and Verdun, A.: The new structure of the International Association of Geodesy (IAG) viewed from the perspective of history, J. Geodesy, 77, 566-575, 2004.

Beutler, G., Drewes, H., and Verdun, A.: The Integrated Global Geodetic Observing System (IGGOS) viewed from the perspective of history, J. Geodyn., 40, 414-431, 2005.

Boucher, C. and Willis, P.: IAG history: The years of world wars and aftermath (1917-1959), IAG Symp., 143, 19-24, https://doi.org/10.1007/1345_2015_96, 2016.
Christodoulidis, D. C., Smith, D. E., Dunn, P. J., Klosko, S. M., Torrence, M. H., Fricke, S., and Blackwell, S.: The SL5 geodetic parameter recovery solution, Proceedings of the International Symposium on The Use of Artificial Satellites for Geodesy and Geodynamics, Athens, Greece, 425-467, 1984.

Drewes, H.: Combination of VLBI, SLR and GPS determined station velocities for actual plate kinematic and crustal deformation models (APKIM), IAG Symp., 119, 377-382, 1998.

Drewes, H. and Adam, J.: The International Association of Geodesy - Historical overview, J. Geodesy, 90, 913-920, 2016.

Guinot, B.: History of the Bureau International de l'Heure, in: Polar Motion: Historical and Scientific Problems, edited by: Dick, S., McCarthy, D., and Luzum, B., ASP Conference Series, 208, 175$183,2000$.

Heiskanen, W. A.: The Columbus geoid, EOS, Transactions, AGU, 38, 841-848, 1957.

Helmert, F. R.: Die internationale Erdmessung in den ersten fünfzig Jahren ihres Bestehens, Internationle Monatsschrift für Wissenschaft, Kunst und Technik, 7, 397-424, 1913.

Kleineberg, A., Marx, Ch., Knobloch, E., and Lelgemann, D.: Die antike Karte von Germania des Klaudios Ptolemaios, Z. Vermessungswesen, 136, 105-112, 2011.

Krüger, L.: Bericht über die Tätigkeit des Zentralbureaus der Internationalen Erdmessung im Jahre 1921, Zentralbureau der Internationalen Erdmessung, Neue Folge der Veröffentlichungen $\mathrm{Nr}$ 39, P. Stankiewicz Buchdruckerei, Berlin, 1922.

Levallois, J. J.: The history of the International Association of Geodesy, Bull. Geod., 54, 249-313, 1980.

Perrier, G.: Ou en est la geodesie?, L'Astronomie, 37, 505-526, 1923.

Schmid, H. H.: Worldwide geometric satellite triangulation, J. Geophys. Res., 79, 5349-5376, 1974.

Schmidt, M., Han, S.-C., Kusche, J., Sanchez, L., and Shum, C. K.: Regional high-resolution spatiotemporal gravity modeling from GRACE data using spherical wavelets, Geophys. Res. Lett., 33, L08403, https://doi.org/10.1029/2005GL025509, 2006.

Tardi, P.: Hundert Jahre Internationale Erdmessung, Z. Vermessungswesen, 88, 2-10, 1963.

Torge, W.: The International Association of Geodesy 1862 to 1922: from a regional project to an international organization, J. Geodesy, 78, 558-568, 2005.

Torge, W.: From a regional project to an international organization: The "Baeyer-Helmert-Era" of the International Association of Geodesy 1862-1916, IAG Symp., 143, 3-18, https://doi.org/10.1007/1345_2015_42, 2016.

Torge, W. and Müller, J.: Geodesy, De Gruyter, Berlin, 4th edn., 2012.

Van de Sande Bakhuyzen, H. G.: Rapport sur l'activité de l'Association Géodésique pendant la periode 1912-1922, Travaux de la Section de Géodésie de l'Union Géodésique et Géophysique Internationale, 1, 1-11, 1923. 